\title{
Modulation of matrix metalloproteinases exerted by Citral in the healing of gastric ulcers in eutrophic and obese animals
}

Rie Ohara (rie.ohara@unesp.br) ${ }^{a}$, Felipe Lima Dario (felipe.lima.dario@gmail.com) ${ }^{\mathrm{a}}$, Gabriela Bueno (gabriela.sbueno17@gmail.com) ${ }^{a}$, Vinícius Peixoto Rodrigues (viniciuspr42@gmail.com)a , Maycon

Tavares Emilio Silva (maycon.silva@unesp.br), Renata Assunção (xreeh15@gmail.com)a, Ana

Carolina Fioretto (fiorettocarol04@gmail.com)a ${ }^{a}$, Lúcia Regina Machado da Rocha (lucia.rocha@unesp.br) ${ }^{a}$, Clélia Akiko Hiruma-Lima (clelia.hiruma@unesp.br)a

a Institute of Biosciences of Botucatu

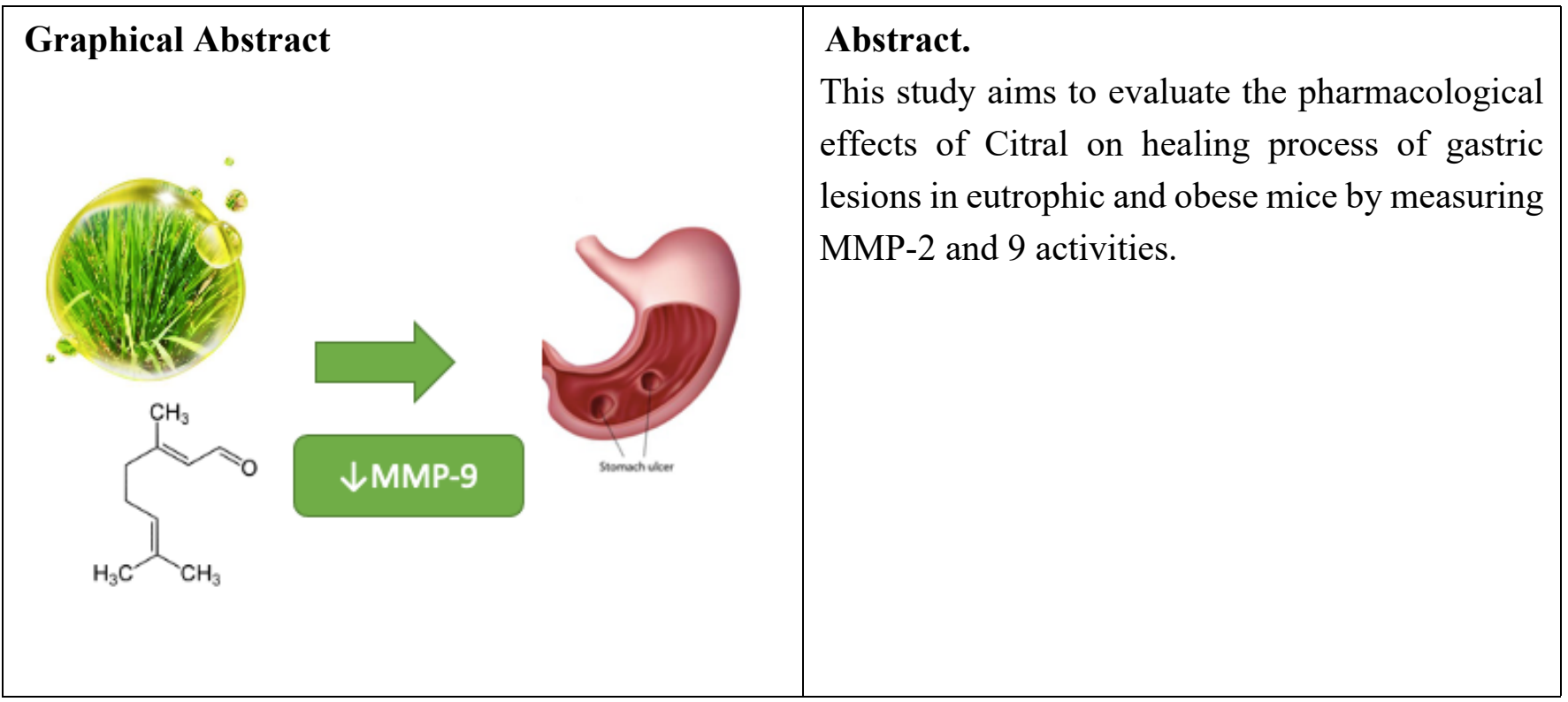

\section{Introduction}

In Brazil, $57.7 \%$ of the adult population is overweight and $19.8 \%$ is obese. Obesity causes a low-grade inflammatory condition that can result in other comorbidities such as type 2 diabetes mellitus, hypertension, hepatic steatosis and atherosclerosis. In addition, in cases of gastrointestinal tract disorders, there is an increase in the severity of gastric lesions and greater difficulty in the healing process, intensified by the use of medications that further aggravate gastric mucosal lesions in obese individuals. Thus, the literature has reported that obesity delays processes such as the healing of gastric lesions and metalloproteinases are intimately related to this difference. These enzymes play a crucial role in ulcer healing, in the initial phase, the role of MMP-9 is highlighted, and in the later phase, MMP2. Studies conducted by our group showed that Citral is able to promote healing acceleration through the modulation of inflammatory mediators in ulcers induced by acetic acid in rats, but its healing action associated with obesity condition is still unknown. 
For induction of obesity, C57B1-J6 mice were divided into 2 groups: Standard diet (SD) and high-fat diet (HFD) and after 12 weeks of dietary intake, the animals underwent gastric ulcer induction surgery by acetic acid. For evaluation of the action of Citral, three doses were orally administrated: 25,100 or $300 \mathrm{mg} / \mathrm{kg}$ for 10 subsequent days and the following groups were included: negative control treated with vehicle (Tween 80 at $1 \%, 10 \mathrm{~mL} / \mathrm{kg}$ ) and positive control treated with Lansoprazole $(30 \mathrm{mg} / \mathrm{kg})(\mathrm{CEUA}$ no 1208). All stomachs were collected for macroscopic morphological and zymographic analysis. The macroscopic analysis of the lesions was performed by quantifying the area of regeneration tissue and the ulcer. In addition, we quantified matrix metalloproteinases 2 and 9 (MMP-2 and 9) by zymography. For statistical analysis, two-way analysis of variance was used, followed by the Tukey or Dunnett test. The minimum significance level adopted for this work was $p<0.05$.

\section{Results and Discussion}

At ten days after the induction of the lesion, it was not possible to detect macroscopically any alteration generated by the treatment with Citral, in any of the tested doses, in relation to the group treated with negative control in the animals fed SD. However, in animals fed with HFD, there was an increase in MMP-9 activity in its intermediate $(50 \%, \mathrm{p}<0.05)$ and active $(13 \%, \mathrm{p}<0.05)$ forms in animals treated with the dose of $100 \mathrm{mg} / \mathrm{kg}$ of Citral. Since MMP-9 is an enzyme that operates in the early phase of ulcer healing and there was no difference between the areas of lesion, the reduction of its activity may indicate that healing process in the group that received the intermediate dose of Citral was in a more advanced stage of healing.

\section{Conclusions}

Although we did not detect macroscopic changes, we found that in obese animals, treatment for 10 days with Citral at a dose of $100 \mathrm{mg} / \mathrm{kg}$ reduced MMP-9 activity, indicating that the healing process may be accelerated in this group.

\section{References}

BOYLAN, M.R. et al. Measures of Adiposity Are Associated With Increased Risk of Peptic Ulcer. Clinical Gastroenterology and Hepatology. v. 12, p. 1688-1694, 2014.

DE CÁSSIA DA SILVEIRA E SÁ, R., ANDRADE, L.N., DE SOUSA, D.P. A review on antiinflammatory activity of monoterpenes. Molecules, 2013.

GADDE, K. M.; MARTIN, C. K.; BERTHOUD, H. R.; HEYMSFIELD, S. B. Obesity: Pathophysiology and ManagementJournal of the American College of Cardiology, 2018.

OKABE, S., ROTH, J.L.A., PFEIFFER, C.J., A method for experimental, penetrating gastric and duodenal ulcers in rats - Observations on normal healing. Am. J. Dig. Dis. 16, 277-284, 1971.

Pesquisa Nacional de Saúde - IBGE. Atenção primária à saúde e informações antropométricas. 2019.

TURNER, J.R. The Gastrointestinal Tract. Robbins \& Cotran Pathologic Basis of Disease. Saunders. Philadelphia, Elsevier: p. 783-784, 2010. 